\title{
Counting Zero: Rethinking Feminist Epistemologies
}

\author{
Xin $\operatorname{Liu} 1 *$
}

Published: October 30, 2017

\begin{abstract}
This article concerns feminist engagements with epistemologies. Feminist epistemologies have revealed and challenged the exclusions and denigrations at work in knowledge production processes. And yet, the emphasis on the partiality of knowledge and the non-innocence of any subject position also cast doubt on the possibility of feminist political communities. In view of this, it has been argued that the very parameter of epistemology poses limitations for feminism, for it leads to either political paralysis or prescriptive politics that in fact undoes the political of politics. From a different perspective, decolonial feminists argue for radical epistemic disobedience and delinking the move beyond the confines of Western systems of knowledge and its extractive knowledge economy. Nevertheless, the oppositional logic informs both feminist epistemologies and its critiques, which I argue is symptomatic of the epistemic habits of academic feminism. This article ends with a preliminary reconsideration of the question of origin through the figure of zero. It asks whether it might be possible to conceive of feminist epistemologies as performing the task of counting zero - accounting for origin, wholeness, and universality - that takes into account specificities without forfeiting coalition and claims to knowledge.
\end{abstract}

Keywords: feminist epistemologies, critique, zero

\begin{abstract}
Much of the most provocative feminist theory in the last twenty years has insisted on the ties of sex and race in ways that problematized the birth pangs of the sex/gender system in a discourse more focused on the interweaving of gender and class. It has seemed very rare for feminist theory to hold race, sex/gender, and class analytically together - all the best intentions, hues of authors, and remarks in prefaces notwithstanding. In addition, there is as much reason for feminist to argue for a race/gender system as for a sex/gender system, and the two are not the same kind of analytical move. And, again, what happened to class? The evidence is building of a need for a theory of 'difference' whose geometries, paradigms, and logics break out of binaries, dialectics, and nature/culture models of any kind. Otherwise, threes will always reduce to twos, which quickly become lonely ones in the vanguard. And no one learns to count to four. These things matter politically (Haraway 1991: 129).
\end{abstract}

For the/a woman, two does not divide into ones. Relationships defy being cut into units. And when 'she' hangs on so desperately to the one, even to the point of putting a capital letter for one god made Man, it is only so as to repeat that value 'she' has a right to upon the exchange market - the value of no value. That nil, that zero, that moving decimal place which is the basis and seal of all accountability (Irigaray 1985: 237).

\section{INTRODUCTION}

A specific, yet familiar scene took place at the 11 th Annual Feminist Theory Workshop held at Duke University in March 2017. In her keynote titled Down with Love: Feminist Critique and the New Ideologies of Work, Kathi Weeks elaborated on the ways in which love has become the mechanism - a new mode of appropriation - that functions to reproduce the figure of the normative worker. Weeks observed the emergence of 'an energetic subject' 1 in

\footnotetext{
${ }^{1}$ Week's talk can be watched at https://www.youtube.com/watch?v=7WOowagkLDE\&t=2483s, last accessed 04.04.2017.
} 
work-life self-help literature, who was capable of self-regulation, understood as a form of intimate investment in work. In the Q\&A session that followed, Weeks' conception of the relation between work and love, as well as of the passionate working subject, were contested for their universalising tendencies. The commentator noted that employers in factories in New Delhi or in Beijing perhaps did not feel the urgency or need to 'construct an ideology'2 of love for work and queried whether there was an implicit elision of the socio-economic differences in Week's theorisation. Week quickly acknowledged the limitation, because of the specificity, of her own argument by clarifying that she looked only within the US context. And she added, "Obviously, I think this is originally targeted to high wage employees."

I recall this scene here not only because of the association of love and critique in feminist theorisations, most tellingly expressed in Sara Ahmed's now well-known assertion 'critique is a labour of love' (2008: 30) as well as in Chela Sandova's theorisation of the methodology of the oppressed as 'a hermeneutics of love (2000: 10.1). But also because it exemplifies a modality of critique where the revelation and insertion of specificities and differences functions as a corrective against generalising gestures. For example, in the dialogue briefly sketched above, the generalisation of the immaterial and affective labour is contested on the basis of the intersectional differences that evoke different relations between love and work. The importance of such a critique is indisputable. And yet, in my opinion, the logic of presence and absence, inclusion and exclusion that such a critique rehearses renders it predictable, and limits the more radical purchase of the problematics of essence and difference. In many cases, a recognition of differences, or an acknowledgement of the blind spot, or limitation, of the theorisation practices, are delivered in response to these critiques. These reflexive gestures then come to stand in as the critical, ethical and political endeavours of feminism. However, two problems arise here. First, the issue of essentialism that undergirds the logic of presence and absence is reinstalled in this assertion of differences. Second, given that partiality is inevitable, the who and what of feminist project presents as a virtual impasse. As Linda Zerilli observes, since a total (feminist) theory cannot exist, we are led to abandon the theoretical enterprise if not the feminist project itself (2005: 36).

This article concerns these conundrums in feminist critical practices. More specifically, it makes visible and engages with various manifestations of oppositional logic in and as, to quote the title of this special issue, 'the epistemic habits of academic feminism'. Rather than repeating the logic of presence and absence, inclusion and exclusion, it zooms in on questions of origin, essence and difference in feminist epistemologies. It proceeds in the following way. First, I provide an overview of some of the key issues in feminist epistemologies, putting emphasis on Donna Haraway's reconfiguration of objectivity. Second, I turn to two lines of critiques against feminist epistemologies. The first account advocates a more radical dismantling of and delinking from the knowledge economy of modernity/coloniality that feminist epistemologies are said to remain embedded in. The second account argues that the difficulties the feminist political project faces reside in the confusion of the political with the epistemological, that is grounded in the deliberative model of rationalism (see Zerilli 2016). Finally, I reconsider the epistemic habits of academic feminism through the figure of zero, that speaks (of) the question of origin and difference. I am aware that these are quite different theoretical frameworks and methodological approaches and that the limited space of this article cannot possibly provide thorough engagements with each paradigm. My aim here, however, is not to provide a comprehensive review of all the theorists' work mentioned here. Rather, it concerns the how of oppositional logical of critique, which as I will show, is key to reconsider feminist epistemologies.

\section{FEMINIST EPISTEMOLOGIES}

The opening scene described above captures the problematics of universality and specificity, or identity and difference, which have been key issues in theorisations of feminist epistemologies. As Claire Colebrook (2017: $448)^{3}$ points out, 'feminism is always the question of who: who speaks, for whom, and whose subjectivity is presupposed in the grammar of the question?' Moreover, the scrutinisation of the universal subject goes hand in hand with feminist contestation of claims of objective knowledge through insisting on asking how we know what we know. Given the emphasis on specificity and difference, it should not be surprising that the term 'feminist epistemology' is often conceived of as an uneasy alliance, if not an 'oxymoron' (Alcoff and Potter 1993: 1).

In their introduction to the anthology Feminist Epistemologies published in 1993, Linda Alcoff and Elizabeth Potter note that feminists' engagements with epistemology have confounded its frame of reference. Typically, traditional epistemology concerns universal and objective knowledge, that is 'knowledge in general'. Its central premises can be summarised in following aspects that concern the subject and the object of the knowledge production process, as well as their relations. First, the subject is understood as unitary, coherent, disembodied,

${ }^{2}$ The Q\&A session is also included in the video linked above.

${ }^{3}$ This is the location number provided in the kindle edition of the book. 
and is capable of simultaneously seeing from nowhere and everywhere. On this account, knowledge, such as theory, is understood to provide a universal account that can be applied to, but is not itself informed by contextual specificities. Second, the object is conceived of as self-present and passive. It provides the fixed ground and raw material/resource for the investigative endeavours of the subject. In other words, to produce knowledge about an object is to re-present and reveal its essence and truth. Third, the subject and the object are separated spatially and temporally. The object is understood as located before, beneath and outside the subject, who codes, deciphers and interprets the world.

This spatio-temporal separation is central to the notion of objective knowledge as a faithful translation of truth. It is informed by and reproduces hierarchical oppositions between culture and nature, mind and body. Such a hierarchisation is also manifested in the subordination of women's everyday 'skilled activity', that is, 'knowing how', to the supposedly proper paradigm of knowledge, that is 'knowing that' (Alcoff and Potter 1993: 11). For example, Vrinda Dalmiya and Linda Alcoff make observations of some of the major factors that were used to justify the denigration and subordination of 'traditional women's beliefs', such as those 'about childbearing and rearing, herbal medicines, the secrets of good cooking', as 'old wives' tales' (1993: 217). As Dalmiya and Alcoff note in the case of midwifery:

midwives often gained their knowledge from their own embodied experience of childbirth ... [which] was empathic, and much of their skill in assisting in childbirth was based on their ability to identify with the expectant mother. This empathy was produced partly by a subjective or first-person knowledge of what it is like (for example) to be a woman going through labor, whereas the knowledge of physicians was grounded in a self-conscious quest for 'objectivity' (1993: 225).

For Dalmiya and Alcoff, the term 'feminist epistemologies' underscores embodied and experiential knowledge production and accommodates a more inclusive framework of epistemology that accounts for objective, intersubjective and subjective modalities. Moreover, it criticises the routine exclusion of women from the subject position of epistemology, because of how women historically have been reduced to the body and thus seen as closer to nature (see for example Pateman and Grosz 1986). Instead of simply including women's experiences into the scene of knowledge production, feminist epistemologies reveal and challenge the political economy of knowledge production, as well as the undergirding violence and moral injunction of the categorical separation of nature and culture (see for example Haraway 2000; Kirby 2011). In so doing, feminist epistemologies call into question the 'nature of knowledge itself', and problematise notions of 'epistemic agency, justification, objectivity', through underscoring 'the impact of the social status as well as the sexed body of the knower upon the production of knowledge' (Alcoff and Potter 1993: 1-2).

A couple of interrelated interventions have been made by feminist scholars working with the question of epistemology: for example, instead of the transcendent and infinite vision, perception and conception are understood as always already mediated by and reproduced by hierarchical relations of power within a specific social context. Moreover, in place of the doctrine of non-contradiction and universal truth, notions of contingency and arbitrariness become central for feminist theoretical and political endeavours. For example, in Bodies that Matter, Judith Butler argues that feminist coalitional politics needs to rework the

logic of non-contradiction by which one identification is always and only purchased at the expense of another (...) in order not to replicate at the level of identity politics the very exclusionary moves that initiated the turn to specific identities in the first place (1993: 118).

Nevertheless, the conception of epistemology as located and multiple, also introduces new problems for the subject of woman. This is because the opposition between specificity and universality, that enables feminist scholars to inquire into the naturalising and disembodied claims of objective knowledge, necessarily entails the impossibility of a single referent of woman ${ }^{4}$. As Donna Haraway points out, the deconstruction of epistemology has also meant that 'no insider's perspective is privileged, because all drawings of inside-outside boundaries in knowledge are theorized as power moves, not moves toward truth' (1998: 576). Given this insight, how might the

\footnotetext{
4 The question of the difference among women and within woman (see Braidotti 1994) has been extensively discussed in feminist scholarly work. For example, as Chandra T. Mohanty writes, “The relationship between 'Woman' (a cultural and ideological composite other constructed through diverse representational discourses - scientific, literary, juridical, linguistic, cinematic, etc.) and 'women' (real, material subjects of their collective histories) is one of the central questions the practice of feminist scholarship seeks to address. This connection between women as historical subjects and the representation of Woman produced by hegemonic discourses is not a relation of direct identity or a relation of correspondence or simple implication. It is an arbitrary relation set up by particular cultures" (2003: 19). Braidotti's nomadic subject and Haraway's cyborg are important efforts.
} 
knowledge claims of women and marginalised others be accounted for without discounting their validity? And how might we account for the differences among women's experiences without prioritizing any perspective?

These questions have posed tremendous challenges to feminist theoretical and political projects. To put the problem in general terms, whose experiences and which identities provide the ground and justification for feminist political alliances? This should also be contexualised in 'the surfacing of 'difference' as the second critical phase in feminist thinking in the late 1979s and 1980s. Griffin's and Bradiotti's observations prove instructive here:

The move in feminism from notions of universal sisterhood and equality of oppressedness within patriarchy, to an understanding of the role that differences among women play in the formation and maintenance of power structures and inequality that affect women differentially, was inter alia spearheaded by black American feminists. (...) Once difference became established as the key concept through which privileged signifier might be critiqued, that concept became transportable into other terrains in which difference had been utilized in the service of oppression and exclusion (2002: 221).

Sandra Harding's conceptualisation of strong objectivity and standpoint theory is an important attempt to navigate through the problematic of identity and difference. This account seeks to take into consideration the intersectional dimension of the subject position, while justifying the need to ground in women's experiences. As Harding makes clear,

standpoint theories of knowledge, whether they are articulated as such, have been advanced by thinkers concerned not only with gender and class hierarchy ... but also with other 'Others'. To make sense of any actual women's life or and gender relations in any culture, analyses must begin in real, historic women's lives, and these will be women of particular races, classes, cultures and sexualities (1991: 151).

And yet, how to see from below remains problematic. In her seminal essay Situated Knowledges: The Science Question in Feminism and The Privilege of Partial Perspective, Donna Haraway voices her misgivings about standpoint theory. Haraway's concern is that standpoint theory's postulation of the innocent vantage point of the subjugated reinstalls a notion of self-same subject whose location is permanently fixed, and whose vision is unmediated by the semiotic technologies of seeing. In concert with Butler's ${ }^{5}$ conception of the epistemic confinement that also characterises the human condition, Haraway argues against narratives of the 'once-upon-a-time wholeness before language, before writing, before Man' (2004: 33) ${ }^{6}$. For Haraway, the various constructions of the primordial coherence of the subject inadvertently recuperates the spatio-temporal gap between nature and culture that underpins the subject/object, mind/matter hierarchies in the first place. In light of this, the problem arises as to how to simultaneously acknowledge the 'historical contingency for all knowledge claims and knowing subjects' without reducing fact or reality simply to rhetoric or form, and 'a no-nonsense commitment to faithful accounts of a 'real' world' (Haraway 1998: 579).

For Haraway, this tension cannot, and in fact, should not be resolved. Instead, the problematic of objectivity and specificity, and the relation between subject and object, could be reconfigured in rethinking the how of knowledge production and the how of vision. As Haraway notes, ' $[\mathrm{v}]$ ision is always a question of the power to see - and perhaps of the violence implicit in our visualizing practices' (1998: 585). If mediation, violence, and corruption are inherent in and integral to any visualising as knowledge production practices, vaguely defined as the process of making the world intelligible, then the strict opposition and separation between the privileged and the subjugated is untenable. Far from 'innocent', understood as unmediated, the subjugated subject position is enabled

\footnotetext{
5 The affinity between Haraway's and Butler's approach is made clear in a footnote where Haraway comments on her understanding of the question of materiality. Haraways writes, "I am using 'matter' in the way suggested by Judith Butler in her work in progress, Bodies [T] hat Matter. ... The marked bodies and subjects theorized by Trinh, Butler, and Wittig evacuate precisely the heterosexist and racist idealism-materialism binary that has ruled in the generic Western philosophical tradition" (Haraway 2004: 61).

${ }^{6}$ In Beyond Identity Politics: Feminism, Power and Politics, Moya Lloyd also comments on Haraway's critique of standpoint theory. The difference between mine and Lloyd's reading lies in the relation between ontology and epistemology in Haraways' theorisations. For Lloyd, Haraway's concern is that in turning towards 'full' and total position', feminist standpoint theory is giving priority to ontology over epistemology. In my reading, Haraway's natureculture approach also effectively rethinks the received gap between ontology and epistemology. In other words, when Haraway writes that '[s] ubjugation is not grounds for ontology; it might be a visual clue' (1998: 586), she is arguing against a particular notion of ontology that functions to, for example, essentialise the 'Third World Woman' (1998: 586). In How Like a Leaf: An Interview with Donna Haraway, Haraway clarifies her stance towards the question of epistemology and ontology. She writes, "One of the things poststructuralism did was to problematize the separation of ontology and epistemology as discourses and I inherit that breakdown" (2000: 78). In my opinion, Haraway is not so much against the prioritising of ontology in feminist standpoint theory as she is concerned with the reinstalled separation between ontology and epistemology in the idea of uncorrupted or unmediated pre-symbolic nature.
} 
by, and participates in, the same field of vision that is informed by particular configurations of relations of power. What Haraway is effectively arguing for here is a notion of complicity ${ }^{7}$, where the subject and the object are implicated in each other. Instead of a mere passive and inert ground before and outside the subject, that awaits inscription, the object - body, nature, Other - is engendered by and engenders the knowing subject as well as the practices of knowledge production. It follows then that objectivity is not abandoned, but rethought as bodily production that is always partial. Such a formulation of objectivity affords Haraway the possibility of accounting for the knowledge claims and experiences of marginalised others, all the while eschewing universalism.

\section{THE PROBLEM OF EPISTEMOLOGY}

Haraway's reworking of epistemology is considered to be in close affinity with third world feminist as well as feminist postcolonial theorisations (see for example Sandoval 2000; Gedalof 1999). For example, for Chela Sandoval, Haraway's cyborg feminism is in line with the 'methodology of the oppressed', for it aims at producing 'a dissident global movement' and rejects any notion of coherent and natural unity or originary wholeness. Nevertheless, as many critics have pointed out, a certain universalising gesture is reinstalled in 'the conflation between women of color as identity, and cyborg feminism as theory' (Sandoval 2000: 170.1). As Sandoval observes,

by gathering up the category 'women of color' and identifying it as 'a cyborg identity, a potent subjectivity synthesized from fusions of outside identities' (i.e., 'Sister Outsider'), her work inadvertently contributes to the elision of differential U.S. third world feminism by turning its approaches, methods, forms, and skills into examples of cyborg feminism (2000: 171.2).

In view of this, the question arises as to whether and how it is possible to develop a feminist theoretical and political project that foregrounds a shared sense of 'we' - that is internally contradictory, as Haraway emphasises - as well as 'our' experiences, without eliding specificities and differences. In this section, I turn to two different critiques against the strands of feminist epistemologies discussed above. First, I draw upon conversation Madina Tlostanova's critique against the coloniality of epistemology (see also Maldonado-Torres 2008). Then I take up Linda Zerilli's suggestion for the separation of the political and the epistemological/philosophical in order to reanimate the political for feminist politics. Despite the differences in their theoretical and methodological approaches, both lines of critiques challenge the residual rationalism in feminist epistemologies and underscore the importance of plurality that is anything but pluralism.

Working within the scholarly field of decolonial feminist theorisations, Madina Tlostanova argues against the 'colonization of knowledge' (2010: 18) which for her limits the critical purchase of feminist epistemologies. For Tlostanova, colonisation of knowledge is a manifestation of the operation of coloniality of epistemology. Tlostanova follows Nelson Maldonado-Torres, who differentiates colonialism from coloniality. As MaldonadoTorres writes,

Coloniality is different from colonialism. Colonialism denotes a political and economic relation in which the sovereignty of a nation or a people rests on the power of another nation, which makes such nation an empire. Coloniality, instead, refers to long-standing patterns of power that emerged as a result of colonialism, but that define culture, labour, intersubjective relations, and knowledge production well beyond the strict limits of colonial administrations (2007: 243).

For Tlostanova, the colonisation of knowledge operates not only in legitimating Western-epistemology as the dominant knowledge system that objectifies the rest of the world, but also in subsuming, appropriating and extracting other knowledge systems for the betterment of Modernity. In view of this, Tlostanova is wary of the logic of opposition or integration that informs some of the most important third world feminist theorisations. In Gender Epistemologies and Eurasian Borderlands, Tlostanova observes these implicit logics in Chandra T. Mohanty's and Jacqui M. Alexander's as well as in Sandoval's theorisations. For example, as Tlostanova argues,

Alexander and Mohanty do not reject the rhetoric of modernity altogether, remaining within its logic though clearly inclining to its socialist pole. Transformation of consciousness and rethinking of identity

\footnotetext{
${ }^{7}$ In Psychic Life of Power: Theories in Subjection, Butler contemplates the question of primary complicity and its political implications. As Butler writes, "The subject might yet be thought as deriving its agency from precisely the power it opposes, as awkward and embarrassing as such a formulation might be, especially for those who believe that complicity and ambivalence could be rooted out once and for all. If the subject is neither fully determined by power nor fully determining of power (but significantly and partially both), the subject exceeds the logic of noncontradiction, is an excrescene of logic, as it were" (1997: 17). While Butler's account of complicity importantly complicates the scene of power's constitution and operation, it nevertheless relies upon an oppositional account of power that I attempt to reconsider here.
} 
are for them the necessary aspects of democracy, seen as a decolonizing practice, while socialism acts as a part of feminist democracy with decolonization at its center. (...) Monhanty and Alexander maintain that feminism must be global and anticolonial, as well as based on socialist principles (2010: 13).

Tlostanova differentiates Mohanty's and Alexander's proposition of 'political decolonization' from what she terms as 'decolonial option' (2010: 11). For Tlostanova, the former's insistence on the socialist principle as the parameter within which transnational feminism is built remains invested in the 'Western modernity's rhetoric of salvation and liberation against the will' (2010: 12). As Tlostanova writes, "there has emerged a number of otherthan-socialist and wider, other-than-modernity models of radical gender resistance in the world. They would not fit the idea of transational feminism if it were based on socialist principles" (2010: 13). In contrast, the decolonial option does not aspire to a universalising or totalising gesture, but insists on 'the pluriversality of contesting projects' (2010: 13).

Whereas Mohanty and Alexander advocate the oppositional positioning of socialist principles against capitalism $^{8}$; Sandoval aims for integration, though not through a unilateral and asymmetrical translation, but 'a double [translation] of the non-Western gender theory into the language of post-modernism and of postmodernist theories into the language of the third world gender discourses' (Tlostanova 2010: 13). Heeding the importance of Sandoval's methodology of the oppressed for 'decolonizing the imagination' (2010: 17), Tlostanova also finds limitation in Sandoval's 'integrative' (2010: 15) framework. For instance, it does not address the operation of the colonisation of knowledge, which is the 'deeper reason' (Tlostanova 2010: 18) for the dismissal of 'the theory and method of oppositional consciousness', that undergirds and connects cross-disciplinary terminologies such as 'hybridity, nomadology, marginalization, Mestiza's consciousness, situated knowledges, strategic essentialism, difference, and schizo-discourse' (2010: 17). For Tlostanova, both the logic of opposition and integration recuperate and run the risk of becoming appropriated by and capitalised upon by the knowledge economy of Western epistemology. This is because binary oppositions are what enable the legitimation, the negation, assimilation and elision of differences by the One/Sameness - Universal, Modern, and Western Epistemology in the first place.

In view of this, Tlostanova proposes the decolonial option that can destabilise the 'extractivist logic of the knowledge economy' (Green 2014) more profoundly. Rather than the totalising and monotopic hermeneutics of the Western epistemology, decolonial thinking proposes 'pluritopic hermeneutics' (Tlostanova 2010: 40), 'border thinking' and 'epistemic delinking' (ibid.: 26). Without going into detailed description of each concept, it suffices to note here that they all underscore a conception of difference that resists being reduced to and elided by sameness. For example, the co-existing and non-hierarchical knowledges are not positioned in the spatial relations of inside and its outside (or the outside of the inside), but on the borders and 'cracks' (Tlostanova 2010: 45) that are 'fragmented' and 'constantly changing' (2010: 44 -45). It follows then that the decolonial option of epistemic delinking also challenges the received notion of inclusion, which continues to be inscribed in the predominant knowledge economy of coloniality/progress/modernity. As Tlostanova makes explicit, 'epistemic delinking, lead[s] to decolonial epistemic shift and bring $[\mathrm{s}]$ forward other principles of knowledge and understanding, an other economy, an other politics and an other ethics' (2010: 26).

Rather than improving or repairing the epistemic system from within through forms of integration and inclusion, or constructing a better or more comprehensive knowledge system, Tlostanova's conceptualisation of the decolonial option attempts to undo the fundamental logic of knowledge embedded in the coloniality/modernity matrix. That is, instead of one system, the decolonial option insists on departing from and being the borders between 'colonial and imperial differences, which were assigned by the dominant discourses to all other people classified as inferior and epistemically disregarded' (Tlostanova 2010: 26). In a similar vein as Haraway's reconsideration of knowledge as fact and fiction, decolonial epistemes challenge the conception of knowledge as objective rationality in their turn to 'folklore, traditional cosmology, religion, nonrational knowledges' (Tlostanova 2010: 26).

Nevertheless, a tension arises in the description of the global project of decolonial practices. For example, in contrast to the universalist and territorial operation of Western epistemic system, decolonial option is understood as a continuous process of differentiation and dis-location that has global reach. As Tlostanova writes,

[d]ecolonial option consciously attempts to get rid of its own possible epistemic provincialism as it opens to more and more locals and contesting epistemic stances along with the original South American basis $\ldots$ beyond $\ldots$ their paradigmatic idea of race, in the direction of intersecting ethnicity, class, and religion (2010: 25-26).

\footnotetext{
8 As Tlostanova explains, "Mohanty and Alexander see capitalism as a set of practices and processes mediated by simultaneous functioning of gender, sexual and racial hierarchies" (2010: 11).
} 
Curiously, in a supposedly humble gesture of offering itself as an option among others, the 'decolonial program' (Tlostanova 2010: 26) starts to resemble Haraway's cyborg feminism in its attempt to unite and bring into conversation 'the multiplicity of oppressed subjects' (2010: 26).

Despite its attempt to move beyond the oppositional logic of difference understood as A/-A, decolonial option seems to rely upon a few pairs of oppositional terms: territorial/border, monotopic/pluritopic, universal/multiple, oppositional/de-linking, appropriation/interaction, dichotomous/dialogical, hierarchical/co-existential. Furthermore, and related to the question of difference, the borders where decolonial thinking is situated are said to be themselves dislocated and fragmented, that is, differentiated. Importantly, this seems to be consistent with the endeavour to decolonise and denaturalise the essentialist account of differences as fixed and unchangeable, that justifies the inferiority of the other. And yet, the presence or location of the border is predicated upon the categorisations of differences produced by the Western knowledge system, or what Tlostanova calls 'colonial and imperial epistemic differences' (2010: 22).

Tlostanova might justify the fixation of these differences that generate the border in terms of the concept of de-linking. That is, to slightly reiterate the foregoing analysis, the most effective contestation of categorical imposition and suppression is the denouncement of its undergirding modernity/coloniality matrix through displacing the hierarchical and monotopic spatial ordering. Nevertheless, in this framework, the figure of the border, as the 'crack' (Tlostanova 2010: 44), the in-between, appears as an entity of sorts, which sits uneasily with the notion of border as fragmented and fractured as Tlostanova proposes. For example, following María Lugones (see for example 2010), Tlostanova suggests that a feminist coalition 'resides in the cracks' (2010: 44), whose subjectivities are multiple and contradictory, which I wish to note is interestingly akin to Haraway's cyborg feminism. And yet, if the border is always broken open and apart, how and where is coalition formed and located? Where does it begin?

The departure point, the identity of feminist coalition, is for Zerilli, one of the major issues for rethinking the political of feminist politics. Her critique against the problem of epistemology for feminism is that it leads to either political paralysis or prescriptive politics that in fact undoes the political (of politics). Although Zerilli's account broaches the question of democracy that are a bit different from the major concerns here, I find her diagnoses of feminist 'epistemological turn' relevant for the discussions about the problem of epistemology. For this reason, I will only briefly bring into conversation Zerilli's advocation of the separation of the political and the epistemological in feminist projects. The upshot of Zerilli's argument is that feminist politics is conditioned upon contingency (see also Wiegman 2012), rather than the predetermined logic of a universal truth. For example, taking issue with standpoint theory as an example of the ways in which feminist political questions are framed in epistemological terms, Zerilli writes,

[F]eminists have been inclined to think about speaking authoritatively in someone's name as a matter of being able to provide foundations of grounds for such speaking. Thinking about political claims as truth claims, feminists have sought to underwrite their action and speech in ways that would, more or less, be unassailable as better if not correct views of the world (2005: 171).

For Zerilli, the received crisis of feminist political and critical projects resides in the fantasy about 'the wholeness of political origins' (2005: 2) of the category of women, which is coupled with the instrumentalist conception of politics as means-to-an-end practices, that are guided and justified by knowledge claims. That is, for instance, the truth of the different experiences and subject positions of women. Unlike the decolonial option that urges to denounce the extractive knowledge economy of the Eurocentric episteme, Zerilli does not consider epistemology's disposition to generalise as necessarily a problem. As Zerilli asks,

is this desire [of giving an exhaustive account of gender relations] unreasonable? Hasn't second-wave American feminist theory itself incited our desire for solace by generation a long chain of causal explanations of women's oppression which, if rightly understood, could be rightly remedied? (2005: 35).

According to Zerilli, the problem lies in the ways in which political claims are explained in terms of knowledge claims. Following Hannah Arendt (see for example 2005)9 , Zerilli argues that political practices are grounded in

\footnotetext{
${ }^{9}$ It is helpful to note how the notion of contingency is understood and utilised differently in Zerilli's and Haraway's respective work. Whereas Haraway writes about the contingency of knowledge and subject formation, Zerilli equates contingency with freedom. For example, as Zerilli writes, "[s]aving truth requires that we take the risk of freedom, even though freedom (i.e., contingency, not necessity, rules in human affairs) also presents grave risks for truth, which gives rise to a paradox of truth for politics" (2016: 137). Zerilli's conception of contingency as freedom draws on Arendt's work, who conceives of freedom in terms of spontaneity and action. As Arendt writes, " $[t]$ he idea that freedom is identical with beginning or, again to use a Kantian term, with spontaneity, seems strange to us because, according to our tradition of conceptual thought and its categories, freedom is equated with freedom of the will, and we understand freedom of the will to be a choice between givens
} 
contingency rather than identity (that is supposedly the justified knowledge about who we are and about our particular experiences), which anticipates or enacts the political space of plurality. In other words, and in a somewhat similar vein as the border thinking proposed by the decolonial option, plurality is synonymous with contingency, that is, not defined by categorical differences. Zerilli's clarification proves helpful here, and I will cite it at length:

$[P]$ lurality requires that we do something in relation to whatever empirical differences may exist: plurality names not a passive state of ontological difference but an active and ... imaginative relation to others in a public space. Plurality, as a political relation external to its terms, is based in the faculty of presentation (imagination) and not - or not initially - in the faculty of concepts (understanding). I can know empirical differences exist as part of the human condition, yet fail to acknowledge them, for the latter act involves more than cognition or the application of concepts to particulars (or, more precisely, where cognition is involved, acknowledgement requires that I do something on the basis of what I know) (2005: 146; emphasis in original).

Positing plurality, that is contingency, as the condition of possibility of the political, Zerilli shifts attention to inter-subjective relations that are non-epistemological. Although I completely agree with Zerilli on the need to eschew prescriptive politics, I wonder about the implications of the separation of the political and the epistemological, and of praxis and theory. Returning to the opening discussion at this point, I have noted the ways in which feminist interventions into the theorisations of epistemology were guided by the political aim of challenging the masculinist conception of universal, disembodied and objective knowledge. As Haraway's confounding of fact and fiction, as well as her critiques against the god trick make clear, feminist epistemologies are critical interventions into the very foundation of the knowledge system of phallogocentrism. In other words, the terms of reference of what counts as knowledge or as proper mode of knowledge production are rethought. This is also relevant to the ongoing feminist debates about the relation between feminism as a political and activist project and as a set of theoretical practices (see also Wiegman 2012). The situatedness or locatedness insisted upon in various strands of feminist theorisations of epistemology are challenges to the divorce between reason/objective rationality and embodied/material contingencies (see for example Pateman and Grosz 1986).

Given this, I wonder whether non-epistemological feminist politics might run the risk of recuperating these divisions that feminist political and theoretical projects have set out to contest. What Zerilli's assertion inevitably raises is the question of why the universality of knowledge claims is unable to adequately approach the question of difference. As Zerilli writes, in framing political claims in terms of knowledge claims, feminism is presented with an impossible choice. That is, feminism either 'acknowledge[s] differences (and risk a subjectivism that effaces truth) or articulate[s] a wrong (and risk an objectivism that effaces difference)' (Zerilli 2005: 138; emphasis in original). Zerilli's observation here is informed by a certain notion of the oppositional relation between universality and specificity, or universal/object knowledge and particular lived experiences. Rather than reconsidering the nature of these underlying assumptions, Zerilli's critique of feminist epistemologies requires the fixation of these oppositions in order to justify an Arendtian conception of politics. For example, although noting that 'there is much to recommend' in Haraway's rejection of both objectivism and subjectivism, and her proposition of the alternative as objectivitiy that is 'partial, locatable, critical knowledges sustaining the possibility of webs of connections called solidarity in politics and shared conversations in epistemology' (Haraway in Zerilli, 2016: 174), Zerilli does not engage further with Haraway's contestation of the split between the object and the subject, as well as Haraway's attempts to rethink the relation between universality and specificity beyond the logic of opposition.

Moreover, in Zerilli's reading, Haraway's theorisation of partiality is translated into accounting for differences, for 'a (more) critical epistemology' (2016: 174). While I concur with Zerilli that the received equation between truth/justification and critical epistemology need to be rethought through, for example, shifting from a subjectcentered conception of judgement, I understand that an important dimension of Haraway's theorisation of situated knowledge is precisely about redefining subjectivity as non-located, because it is internally split and always already inter-subjective. In Zerilli's account, conception and cognition comes after the originary moment of political action. But it is unclear where inter-subjective validity (which for Zerilli is the basis of political claim) ends and subjective conception begins? What can it mean to posit conception as located squarely within the individual subjective realm? Does this in some ways reinstall the mind/matter division that feminist epistemologies have sought to contest? ${ }^{10}$

or, to put it crudely, between good and evil. We do not see freedom as simply wanting this or that to be changed in some way or other" (2005: 113).

${ }^{10}$ In my reading, Zerilli has been trying to think further these questions in her recent comment on affect theory. For example, she writes, "Affect and cognition are not two different systems but radically entangled. ... Can we describe the radical entanglement of affect and conceptual rationality in a way that keeps their mutual imbrication from sliding into always already affectively primed responses, on the one hand, or always already conceptually determined responses, on the other hand? This is the real problem - the problem of a critical judgement - raised at once by and for affect theory" (2016: 261). 
My point here is not to say that Zerilli misreads Haraway, but to point out the ways in which critiques often begin and end by producing the oppositions and conceptions that they set out to challenge, or that could have been pushed further. In view of this, and given that feminist epistemologies are decisively about location and the departure point of enunciation, I will now turn to the figure of zero.

\section{COUNTING ZERO}

In this article, I have tried to make visible the epistemic habits in the diverse and often contradictory theorisations and critiques of feminist epistemologies, as the ones outlined here. More specifically, I have tried to think further about what relations between universality and plurality are evoked, and how the questions of origin and differences are understood, in feminist critiques of epistemology. I show that despite the different endeavours to eschew the universal tendencies of epistemology, and to provide anti-essentialist accounts of difference, feminist theorisations of and against epistemology often begin and end by producing an oppositional account of difference. Moreover, and interestingly, despite their differences, these accounts are informed by an explicit or implicit disavowal of the notion of origin.

Typically, origin is associated with self-sameness and wholeness, and implies a conception of nature and bodies as fixed and immutable. It has two functions that are particularly relevant for the discussions at hand. First, posited as a homogeneous unity, the origin is conceived of as containing the essence which verifies the objectivity of knowledge and the truth of an identity. Second, and relatedly, informed by notions of progress, the simplicity of origin (nature) provides the point of departure that the evolved complexity (culture) is measured against. Such a configuration provides justification for various sexualised and racialised conceptions of knowledge. For example, as noted earlier, women's knowledge (knowing how) was not regarded as knowledge proper (knowing that), because it is embodied and affective.

It could be said that the rejection of the notion of origin in feminist epistemologies is an important endeavour against essentialising, sexualising and racialising conceptions of knowledge. And yet, and interestingly, this original wholeness is often recuperated in feminist emphasis on differences among women and the contingency of knowledge. For example, as Zerilli observes,

The breathless pace with which members of the earliest second-wave feminist groups split off to found other groups, only to find members of the new group splitting off to found yet other groups, indicates what we might call a retroactive fantasy about the wholeness of political origins (2005: 1-2).

As I have sought to show, the received notion of the causal determination of the originary wholeness is implicitly recuperated in being contested in feminist rethinking of epistemology. For example, in Haraway's assertion of the implicatedness of the subject and the object, as well as the necessary partiality and locatedness of the process of knowledge production, the notion of origin is rejected, for it connotes purity, unity and wholeness, which for Haraway is the Western fantasy that ultimately serves the domination and control of Man. However, this sense of origin is kept alive as it provides the ground against which the multiplicity and partiality of situated knowledge and the cyborgian subjectivities are defined. In a similar vein, the universalist notion of 'the common origin of all human beings' (2010: 22), as well as its concomitant epistemic scheme, are necessitated in Tlostanova's formulation of border thinking as the epistemology of the exterior. In fact, this is made explicit in the Tlostanova's following clarification,

Border thinking is the epistemology of the exteriority that is of the outside created from the inside ... But this is not a simple change of one (Western) epistemology to another or others. All the models continue to exist and remain viable as sources and targets of criticism (2010:26).

How then might it be possible to call into question the received notion of origin as pure and whole that does not reinstall it in its negation? This section zooms in on this problematic. As I will show, a critical rethinking of the notion of origin, and its correlated terms such as nature, essence and whole, is central for reconfiguring feminist habits of critique, and relatedly, feminism as a theoretical and political project. Given that many discussions in feminist theorisations of epistemology center on the difference between the One and the multiple, I approach the question of origin through performing the task of counting zero.

At the beginning of this article I quoted Donna Haraway and Luce Irigaray as they both touch upon the issue of counting, that is how to count, account for, take into account, differences and specificities. Whereas Haraway suggests counting to four, Irigaray points out the impossibility of counting. In what follows I will first elaborate on their different positions vis-à-vis counting. As the quote makes clear, Haraway asks us to consider the possibility of rethinking differences (counting to four) among women, rather than remaining trapped in the logic of Man/Others, A/-A. As Irene Gedalof also comments on the same quote: 
Haraway's arithmetical challenge to feminism - that is learn 'to count for four' - is a call to think about the paradigm shifts that would problematize many of the assumptions about ontology, power and language that much of feminist theory still takes as its starting points (1999: 146).

For Haraway, in order to achieve affinity in politics (rather than grounding politics in an essentialist notion of affinity and identity) and to dismantle the command and control of (Western) knowledge system, it is of utmost importance to entirely abandon the dualistic paradigm that is constituted by and reproduces Sameness. Although mentioned only briefly in her writing, it seems to me that the question of zero is key for understanding the possibilities and impossibilities of counting to four that Haraway proposes. In A Manifesto for Cyborgs, Haraway reveals the production and denigration of Otherness in the dualistic formulation of the subject. As she writes:

Every story that begins with original innocence and privileges the return to wholeness imagines the drama of life to be individuation, separation, the birth of the self, the tragedy of autonomy, the fall into writing, alienation; i.e., war, tempered by imaginary respite in the bosom of the Other. These plots are ruled by a reproductive politics - rebirth without flaw, perfection, abstraction. ... But there is another route to having less at stake in masculine autonomy, a route that does not pass through Woman, Primitive, Zero, the Mirror Stage and its imaginary (2004: 34-35).

The figure zero here relates to Jacques Lacan's theorisation of the process of subject formation. To put simply, in the Oedipal structure, zero is understood as a plenitude that acquires identity and becomes one only in relation to the signifier phallus by the name-of-the-father (see Grosz 1990). This is in fact criticised in both Irigaray's assertion of the impossibility of counting and Haraway's provocation of counting to four. Although it is impossible here to provide a thorough account of Lacan's psychoanalytic account of zero, for my analysis, it is important to understand how it is interpreted and challenged in Haraway's and Irigaray's respective work.

Haraway's argument for another route of becoming that is grounded in the ordinary everyday life for survival rather than 'through Woman, Primitive, Zero, the Mirror Stage and its imaginary' could be read as a critique against the logic of reproduction, which is ultimately about the progressive continuity of One/Man. The movement from zero to one is the process of abstraction and extraction, symptomatic of the Western/Masculine/Colonial system of knowledge production. Retrospectively understood as the 'little' man' (Grosz 1990: 102), zero is not so much a neutral space as it is always already defined through a certain notion of sexual difference and reproduction. Calling into question the received necessity or inevitability of the Oedipal paradigm of the knowing subject - zero becoming one, 'if it does so' (Grosz 1990: 104), Haraway's account of situated knowledge posits the subject as always and simultaneously partial and multiple. That is, it constitutes and is constituted by the object, the bodily apparatus as well as other relations of knowledge production. This seemingly contradictory simultaneity also radically reconfigures what one is. That is, unlike in the Western/Masculine/Colonial system of knowledge where $1+1+1+1=1$, in the formulation of situated knowledge production $1+1+1+1>4$. In my opinion, it is in this sense, that it is possible to begin to count to four. And yet, on this account, zero is simply negated rather than reconfigured.

In contrast, Irigaray finds critical purchase in the ways in which zero functions as the condition of possibility for the operation of the Law of the Father. For Irigaray, zero presents the radical debt for each speaking subject. That is, as the (w)hole, the (m)other, zero presents the unity that is uncalculatable and inaccessible. For Irigaray, the episteme is grounded in the illusion of the one, the individual, so that it can 'count everything, to number everything by units, to inventory everything as individualities' (1985: 26). And yet, zero - the (w)hole, the (m)other - exceeds such a numerical measurement, and 'resists all adequate definition' (Irigaray 1985: 26). She is the outside, 'the negative, the underside' (Irigaray 1985: 26) of the knowledge economy of accumulation, division and appropriation. She is the zero, the nil, the none. "Neither 'one' nor 'two"' (Irigaray 1985: 207). Rejecting an account of difference that remains within the phallogocentric confinement, Irigaray asserts:

We are luminous. Neither one nor two. I've never known how to count. Up to you. In their calculations, we make two. Really, two? Doesn't that make you laugh? An odd sort of two. And yet not one. Especially not one. Let's leave one to them: their oneness, with its prerogatives, its domination, its solipsism: like sun's (1985: 207).

And yet, the zero is still 'counted as none' (Irigaray 1985: 26; emphasis added). Or to recall my reading of Haraway's rejection of zero, it could be said that the received notion of zero as the originary plenitude is always already informed by the Oedipal structure. Irigaray concedes an originary wholeness to zero, which as Vicki Kirby observes, 'precedes the rupture of copula-tion (becomings), as if, in simply terms, it just is' (2011: 131). Given this radical outsideness, it is unclear how this 'pure, isolated' (Kirby 2011: 130) origin comes to be counted as zero, 
which, as I will shortly show, is far from absolute nothing ${ }^{11}$. It seems then that whereas Haraway abandons zero to reconfigure one, Irigaray calls into question the phallogocentric illusion of masculine autonomy by revealing the promise and threat of the radical debt that zero is.

How might this reading of zero assist my concern here about the habits of feminist critique? As my foregoing analysis has hopefully shown, on both accounts, the received notion of zero as originary wholeness is conceded to (in Haraway's theorisation it is installed in being refused). And as I have tried to make explicate, both feminist critiques against traditional epistemologies, and against feminist epistemologies, remain invested in the selfevidence of origin - its wholeness and universality - even in the form of negation. At the risk of providing somewhat of a caricature, it could be said that feminist theoretical and political endeavours often concern the question of identity and difference. That is how the specificities might be taken into account and accounted for, all the while building alliances and coalitions. Notwithstanding the different turns in feminist scholarly field, the relation between the One and the multiple continues to inform feminist debates, and is often conceived of as an inevitable impasse.

Given this, in what follows I provide a preliminary account of counting zero. My point is not to suggest that such a rethinking provides the corrective of or the solution to the received tensions in feminist debates. Instead, I argue that if zero as origin is never simply homogenised and unified, any more than specificities are complex and multiple, then the various forms of critique that ground in their opposition also need to be rethought.

So what does it mean to count zero? The difficulty of this question resides in the puzzles of thinking about zero. First, zero is a meta-number. That is, it 'stands for the absence of number, any number' (Miller 2003: 47). In this case, it could also be used as a placeholder for any particular number. For example, consider the number 2017 and 2107. Whereas in the former zero stands for 100, in the latter it stands for 10. Second, zero is the container of all numbers. That is, it generates infinite numbers. Third, to complicate the matter even further, the signification of zero as the origin of all numbers and/or the absence of any number, is conditioned upon the preposition 'of'. In other words, zero cannot be understood separately from the number that it generates or lacks.

What I am getting at is a sense of radical implicatedness that also makes visible the ways in which zero, as origin, is never simply whole, any more than it is absolutely lacking. Interestingly then, zero seems to be simultaneously whole and part, universal and specific, nothing and everything. In view of this, might it be possible to entertain the possibility of not simply conceding to the presence of origin, or rejecting it because it seems that 'when we search for an origin we inevitably discover contemporary preconceptions and desires in the nature of its identity' (Kirby 2011: 142)? In other words, if zero implicates and is implicated in its multiple and contradictory manifestations, then it could also be said, that the terms of reference of opposites, such as universality and particularity, can be affirmed, refused and reconfigured. It follows then that critique is a labour of love, not because it is opposite to opposition, but because the radical implicatedness of which zero is an expression of, means that contradiction and opposition are internal to love's operation.

In this article, I have sought to make visible the ways in which oppositional logic operates as a habit of critique in feminist reconfigurations of epistemology. I have shown that despite their differences in terms of theoretical frameworks and methodological approaches, one of the shared political and ethical commitment of feminist (critiques of) epistemologies is to contest forms of transcendence (for example the conception of epistemology as disembodied objective knowledge) and the exclusion and marginalisation of otherness. And yet, the difficulty remains as to how see from the vantage point of others without reproducing essentialist notion of identity. In their attempt to eschew fixation, feminist critics seek to ground knowledge production and politics in the contingency of Otherness. On these accounts, questions of origin, whole and universality are routinely disavowed as illusions that are engendered by and engender the coloniality of knowledge centered on the figure of Man coded as white and masculine. Nevertheless, as the critiques of Haraway's cyborg feminism and my reading of Tlostanova's conception of pluritopic hermeneutics have hopefully shown, the political and ethical commitment to specificities cannot easily do away with forms of abstraction, extraction and opposition. Moreover, and relatedly, in positing the others as equally outside and below the hegemonic order, their differences, variations and contradictions are sidelined.

Does feminist commitment to specificities necessarily lead to prescriptive politics that compulsively reproduces, in the hope of including, differences rather than attending to 'differences that matter' (Ahmed 1998)? Is the received tension between universality and specificity inevitable and irreconcilable? And is severing the political from the epistemological the only viable option? My preliminary account of zero is an attempt to reconsider these conundrums and the oppositional logic that informs feminist habit of critique. Although the theorisations discussed here all underscore complicity, and contest oppositional account of critique, they rely upon forms of distance from notions of origin and whole in the first and last instance. Interestingly, notwithstanding their vehement challenges to fixation and essence, the nature of origin and whole is not itself in question. In counting

11 As Robert Kaplan writes, zero 'is a nothing that is an actual something’ (2000: 14).

(C) 2017 by Author/s 
zero, I argue that the identity of zero, origin and whole is not self-present, but implicates and is implicated in specific manifestations, differently. Rather than producing oppositions of opposition, or critiques of critique (see for example Felski 2015), I suggest that counting zero affords a modality of critique that activates the political of feminist politics understood as simultaneously located, specific, contradictory and original.

\section{REFERENCES}

Ahmed, S. (1998). Differences That Matter: Feminist Theory and Postmodernism. Cambridge: Cambridge University Press.

Ahmed, S. (2008). Open Forum Imaginary Prohibitions: Some Preliminary Remarks on the Founding Gestures of the 'New Materialism'. European Journal of Women's Studies. 15(1), pp. 23-39.

Alcoff, L. and Potter, E. (1993). Introduction: When Feminisms Intersect Epistemology. In: L. Alcoff and E. Potter, eds., Feminist Epistemologies (pp. 1-14). New York and London: Routledge.

Arendt, H. (2005). The Promise of Politics, edited and with an introduction by Jerome Kohn. New York: Schocken Books.

Braidotti, R. (1994). Nomadic Subject: Embodiment and Sexual Difference in Contemporary Feminist Theory. New York: Columbia University Press.

Butler, J. (1993). Bodies that Matter: On the Discursive Limits of "Sex". New York and London: Routledge.

Butler, J. (1997). Psychic Life of Power: Theories in Subjection. Stanford: Stanford University Press.

Colebrook, C. (2017). We Have Always Been Post-Anthropocene: The Anthropocene Counterfactual. In: R. Grusin, ed., Anthropocene Feminism (kindle version). Minnepolis and London: University of Minnesota Press.

Dalmiya, V. and Alcoff, L. (1993). Are “Old Wives' Tales" Justified?. In: L. Alcoff and E. Potter, eds., Feminist Epistemologies (pp. 217-244). New York and London: Routledge.

Derrida, J. (1978). Writing and Difference. Chicago and London: The University of Chicago Press.

Derrida, J. (1998). Monolingualism of the Other; or, The Prosthesis of Origin. Stanford: Stanford University Press.

Gedalof, I. (1999). Against Purity: Rethinking Identity with Indian and Western Feminisms. London and New York: Routledge.

Green, L. (2014). Ecology, Race, and the Making of Environmental Publics: A Dialogue with Silent Spring in South Africa. Resilience: A Journal of the Environmental Humanities, 1(2). https:/ / doi.org/10.5250/resilience.1.2.002

Griffin, G. and Braidotti, R. (2002). Whiteness and European Situatedness. In: G. Griffin and R. Braidotti, eds., Thinking Differently: A Reader in European Women's Studies (pp. 221-236). London and New York: Zed Books.

Grosz, E. (1990). Jacques Lacan: A Feminist Introduction. London and New York: Routledge.

Felski, R. (2015). The Limites of Critique. Chicago and London: The University of Chicago Press.

Haraway, D. (1991). Simians, Cyborgs and Women: The Reinvention of Nature. London: Free Association Books.

Haraway, D. (1998). Situated Knowledges: The Science Question in Feminism and the Privilege of Partial Perspective. Feminist Studies, 14(3), pp. 575-599.

Haraway, D. (2000). How Like a Leaf: An Interview with Thyrza Nichols. New York and Oxon: Routledge.

Haraway, D. (2004). The Haraway Reader. New York and London: Routledge.

Harding, S. (1991). Whose Science? Whose Knowledge?: Thinking from Women's Lives. New York: Cornell University Press. Irigaray, L. (1985). This Sex Which Is Not One. Ithaca: Cornell University Press.

Kaplan, R. (2000). The Nothing that Is: A Natural History of Zero. Oxford: Oxford University Press.

Kirby, V. (1997). Telling Flesh: The Substance of the Corporeal. New York and London: Routledge.

Kirby, V. (2011). Quantum Anthropologies: Life at Large. Durham and London: Duke University Press.

Lloyd, M. (2005). Beyond Identity Politics: Feminism, Power \& Politics. London, Thousand Oaks and New Delhi: Sage.

Lugones, M. (2010). Toward a Decolonial Feminism. Hypatia, 25(4), pp. 742-759.

Maldonado-Torres, N. (2007). On the Coloniality of Being. Cultural Studies, 21(2), pp. 240-270.

Maldonado-Torres, N. (2008). Against War: Views from the Underside of Modernity. Durham and London: Duke University Press.

Miller, H.J. (2003). Zero Plus One. Valencia: University de Valencia.

Mohanty, C.T. (2003). Feminism without Borders: Decolonizing Theory, Practicing Solidarity. Durham and London: Duke University Press.

Pateman, C. and Grosz, E. (1986). Feminist Challenges: Social and Political Theory. Sydney: Allen \&Unwin Australia.

Sandoval, C. (2000). Methodology of the Oppressed. Minnepolis and London: University of Minnesota Press.

Tlostanova, M. (2010). Gender Epistemologies and Eurasian Borderlands. New York: Palgrave Macmillan.

Wiegman, R. (2012). Object Lessons. Durham and London: Duke University Press.

Zerilli, L.M.G. (2005). Feminism and the Abyss of Freedom. Chicago and London: The University of Chicago Press.

Zerilli, L.M.G. (2016). A Democratic Theory of Judgement. Chicago and London: The University of Chicago Press. 
Citation: Liu, X. (2017). Counting Zero: Rethinking Feminist Epistemologies. Feminist Encounters: A Journal of Critical Studies in Culture and Politics, 1(1), 07. https://doi.org/10.20897/femenc.201707

Copyright (C) 2017 by Author/s and Licensed by Lectito BV, Netherlands. This is an open access article distributed under the Creative Commons Attribution License which permits unrestricted use, distribution, and reproduction in any medium, provided the original work is properly cited. 